\title{
Introducción. Discurso metalingüístico e ideologías en el periodismo de opinión
}

\section{Introduction. Metalinguistic discourse and ideologies in Opinion Journalism}

\author{
Susana Guerrero Salazar (iD ${ }^{1}$, Carmen Marimón Llorca (iD ${ }^{2}$ \\ Universidad de Málaga, Málaga, España \\ salazar@uma.es \\ Universidad de Alicante, Alicante, España \\ marimon@ua.es
}

ACCESO ABIERTO / OPEN ACCESS

Cita: Guerrero Salazar, Susana y Marimón Llorca, Carmen (2020). Introducción. Discurso metalingüístico e ideologías en el periodismo de opinión. Textos en Proceso, 6(2), pp. 1-6. https://doi.org/10.17710/tep.2020.6. 2.1guerreromarimon

Editoras: Susana Guerrero Salazar y Carmen Marimón Llorca

Recibido: 30/11/2020

Aceptado: 05/12/2020

Conflicto de intereses: Las autoras han declarado que no poseen conflicto de intereses.

Copyright: @ Susana Guerrero Salazar y Carmen Marimón Llorca. Esta obra está bajo licencia Creative Commons Reconocimiento 4.0
Hablar sobre la lengua es una actividad natural, producto de la capacidad metarreflexiva de los hablantes que nos permitimos juzgar y opinar sobre qué, desde nuestra perspectiva, nos parece incorrecto, nuevo, bonito o malo en la lengua de nuestra comunidad lingüística y social. Esta capacidad de opinar tiene una vertiente socio-discursiva en los discursos metalingüísticos que se divulgan a través de los medios de comunicación. Estos ya no constituyen meras opiniones, sino que desempeñan un papel relevante en la transmisión de conocimiento, valores y normas sobre la lengua en relación con sus contextos sociales e ideológicos concretos. Periodistas recogiendo puntos de vista, pero también autores de reconocido prestigio lingüístico, autoridades institucionales, educadores, políticos, legos y aficionados a la lengua, vierten sus opiniones en periódicos, radios y televisiones, en blogs personales o en páginas especializadas construyendo comunidades discursivas que generan opinión y acaban construyendo distintos imaginarios sobre la lengua.

El objetivo de este monográfico ha sido reunir trabajos que aborden el análisis del discurso metalingüístico que se hace desde el periodismo de opinión y su papel en la transmisión de determinadas ideologías lingüísticas. Los autores y autoras abordan temas diversos. Algunos tienen que ver con la construcción textual de los textos de opinión sobre la lengua -la mayoría de ellos columnas sobre la lengua (CSL) - y cómo determinados recursos contribuyen a la construcción de imaginarios sobre la lengua. Es el caso de los trabajos sobre la polifonía (Pano Alamán), el humor (Gómez Sánchez), los inicios y cierres (Cortés Rodríguez) y las metáforas (Marimón Llorca); Azorín y Santamaría analizan cómo se aborda el léxico en las columnas en relación con el Diccionario, Poch Olivé estudia los textos en perspectiva contrastiva y Sánchez Manzanares se refiere al análisis de la comunicación política. Finalmente, un grupo de tres trabajos (Guerrero Salazar, 
Martínez Linares y Martínez Egido) se centran en el análisis de la polémica sobre el lenguaje igualitario y en el componente ideológico que este lleva consigo.

En el conjunto general de la textualidad metalingüística, destacan en particular un tipo de textos, las columnas sobre la lengua (CSL) que se pueden definir como "textos que tratan sobre la lengua, publicados en la prensa que constituyen la expresión libre de la ideología lingüística de un individuo que, con periodicidad, vierte sus opiniones sobre el uso que sus contemporáneos realizan de ella" (Marimón Llorca, 2019, p. 14). Desde hace algún tiempo, estos textos están siendo objeto de atención por parte de investigadores que ven en ellos un testimonio vivo de cómo se producen y se perciben los procesos de cambios en la lengua incluso en periodos que, desde el punto de vista diacrónico, podrían suponerse cortos. La sincronía dinámica en la que está implicada la lengua encuentra en este tipo de textos una prueba excepcionalmente relevante por su propia naturaleza individual y social, culta y popular, mediática y académica. La publicación de la Revista Circula (2015), la emergencia, en 2016, del Proyecto de investigación METAPRES FFI2015-65917-P "El discurso metalingüístico en la prensa española (1940-hoy). Análisis multidimensional y caracterización genérica" supusieron el inicio de la puesta en valor como objetos de interés lingüístico de este tipo de textos. Numerosas publicaciones, además de la celebración de Congresos (ILPE), Seminarios y Jornadas en universidades españolas, europeas y norteamericanas dan idea de la repercusión en el campo de la investigación lingüística que van teniendo las CSL. Este año 2020 el trabajo realizado mantiene su continuidad con la concesión del Proyecto METAPRES-COLING PID2019-107265GB-I00 "El columnismo lingüístico en la prensa española desde sus orígenes. Análisis multidimensional, caracterización y aplicaciones", cuyo objetivo es continuar con el análisis y sistematización de este tipo de textos ahora también desde sus inicios en el siglo XIX. Aunque ambos proyectos se han ocupado de estudiar distintos aspectos de las columnas - la composición, los recursos (argumentación, ironía), los objetos de análisis (léxico, sintaxis, neología...), los temas (sexismo lingüístico, autoridad, Academia) etc.- un factor común a todos ellos ha sido la toma de conciencia del componente ideológico que se transmite a través de ellas. El estudio de las ideologías lingüísticas es también un asunto emergente cuyo análisis quiere poner el acento en la no neutralidad del lenguaje y en las implicaciones sociales y políticas que trae consigo el debate público sobre la lengua.

En este sentido se sitúa el Proyecto de investigación DISMUPRESN P18RT-1300 "El discurso metalingüístico sobre «mujer y lenguaje» en la prensa española: Análisis del debate lingüístico y su repercusión social", que surge para llenar un vacío, pues no se ha abordado en profundidad el proceso de construcción del discurso de la prensa española con respecto a la feminización del lenguaje, esto es, todo lo concerniente a sexismo lingüístico, lenguaje inclusivo, etc., estudiando tanto los temas que son noticias, las fuentes, los elementos de significación de contenidos, como la repercusión social del debate generado, teniendo en cuenta los comentarios que se hacen a las noticias, las cartas al director, las columnas de opinión, etc. Uno de los objetivos del proyecto es la recopilación, sistematización y análisis del debate ideológico que el tema "mujer y lenguaje" está suscitando. Se trata de caracterizar los textos seleccionados en relación con sus contextos sociales e ideológicos para mostrar las principales tendencias de cambio con respecto a la feminización del lenguaje desde finales de los sesenta hasta la actualidad (como 
vamos a mostrar más adelante, en esta línea se sitúan los trabajos de Guerrero Salazar, Martínez Egido y Martínez Linares).

El presente monográfico reúne diez trabajos de hispanistas en los que se aborda, desde diferentes perspectivas, el análisis de textos metalingüísticos pertenecientes al periodismo de opinión y se evidencia su implicación en la transmisión de ideologías sobre la lengua.

Dolores Azorín Fernández y M. ${ }^{a}$ Isabel Santamaría Pérez presentan, en "La evolución del léxico en el DRAE a través de las columnas sobre la lengua. Casares y 'La Academia esapañola trabaja'", un estudio detallado sobre la forma en que el nuevo vocabulario es tratado en las columnas sobre la lengua y hasta qué punto el rechazo o la aceptación de este por parte de los columnistas coincide con los criterios de la Academia a la hora de incorporar nuevo vocabulario. El corpus de voces, extraído de columnistas de tres décadas, se distribuye en los tres grupos que, desde siempre, han sido objeto de controversia a la hora de incluirlos en los repertorios léxicos. Se trata de los tecnicismos, los neologismos, especialmente préstamos de otras lenguas, y las expresiones coloquiales. Con el fin de comprender los criterios de selección de determinado léxico por parte de la Academia para su inclusión en el Diccionario se tienen en cuenta factores como el análisis de la frecuencia de uso. El artículo manifiesta la resistencia secular a la incorporación de neologismos y las implicaciones ideológicas que comporta este tipo de actitud tanto por parte de la Academia como por la de los columnistas.

En su trabajo "Recursos para el relieve de inicios y cierres en la columna lingüístico-periodística”, Luis Cortés aborda el tema de la construcción lingüísticodiscursiva de este tipo de textos. A partir de la idea del enseñar deleitando horaciano y de la organización retórica del texto, el autor analiza columnas procedentes de la recopilación El habla nuestra de cada día (Cortés, 2019) con el fin de sistematizar los patrones de inicio y cierre de este tipo de textos. Por lo que se refiere a los de inicio, destaca cinco recursos: las citas, generalmente literarias; algunos dichos y sus orígenes; noticias sobre hechos recientes; alguna experiencia personal, y correspondencia de lectores. De ellos se centra en tres, las citas, los dichos y las noticias. En cuanto a los cierres, destaca el valor persuasivo-estético que tienen la mayoría de ellos y el hecho de que, en numerosas ocasiones no aparezcan solos, sino formando combinaciones de varios recursos -hasta tres-. Por orden de frecuencia señala: el dictamen final del autor, la cita, el anuncio del capítulo siguiente y un apunte irónico. El autor ilustra su trabajo con análisis y ejemplos concretos del corpus y abre, así, la posibilidad a un trabajo más amplio que confirme la existencia de dichos patrones compositivos en las columnas sobre la lengua.

"Humor y registros lingüísticos: un análisis de las columnas Cuarentena en la España vacía, de Daniel Gascón" da nombre al trabajo de M. ${ }^{\mathrm{a}}$ Elena Gómez Sánchez, quien analiza desde la perspectiva del análisis del discurso seis columnas literarias publicadas por Daniel Gascón en el diario El País en el mes de agosto de 2020; se trata de seis relatos sobre las aventuras de Enrique Notivol, el protagonista de su novela Un hípster en la España vacía, que permiten reflexionar sobre la lengua desde una perspectiva tanto seria como lúdica. El objetivo es desentrañar algunos de los mecanismos lingüísticos que ponen de manifiesto el sentido humorístico del escritor (entre los que se incluyen también referencias explícitas a conceptos lingüísticos), así como los registros empleados por los distintos personajes que aparecen y que contribuyen a caracterizarlos. Esto ha permitido reflexionar sobre determinados imaginarios lingüísticos y el modo en el que estos 
pueden encontrarse en la prensa. El trabajo demuestra cómo el empleo de recursos como las hipérboles, los contrastes, las paradojas, los términos tabú o las referencias explícitas a teorías lingüísticas contribuyen a caracterizar discursivamente a los personajes como pertenecientes al mundo rural, frente al hípster procedente de la ciudad.

En el artículo "Los dardos' de Lázaro Carreter al lenguaje de género", de Susana Guerrero Salazar, a partir del concepto de ideología lingüística y de las propuestas metodológicas para el Análisis Crítico del Discurso, se analiza un corpus de columnas sobre la lengua de Fernando Lázaro Carreter, procedentes de El dardo en la palabra (1997) y de El nuevo dardo en la palabra (2003), las cuales abordan la feminización del lenguaje en cualquiera de sus manifestaciones. El objetivo del análisis es determinar qué temas se tratan en estas columnas, qué relación guardan con sus contextos históricos y cómo manifiestan la ideología del columnista. El trabajo demuestra que en el Nuevo dardo se introducen dos temas que no aparecían en el primer Dardo, pues son fruto de la actualidad del momento. Por un lado, los procedimientos igualitarios (principalmente las formas desdobladas del discurso político) y, por otro, el uso de la palabra género (procedente del anglicismo gender). Para mostrar su desacuerdo con ambos temas, Lázaro Carreter emplea los mismos argumentos que la Academia Española ha seguido defendiendo posteriormente tanto en sus obras de referencia como a través de los medios de comunicación y de las redes sociales, convirtiéndose así en el primer y más destacado académico en difundir la argumentación de la RAE en torno al lenguaje inclusivo en el periodismo de opinión.

Carmen Marimón Llorca se propone en "«Un Diccionario no debe taparse los ojos ante la realidad». Metáforas sobre la lengua e ideología en el columnismo lingüístico académico" analizar la funcionalidad discursiva de las metáforas metalingüísticas en un corpus de textos formado por columnas sobre la lengua escritas por autores académicos. El corpus está compuesto por treinta columnas publicadas por Zamora Vicente, Seco y Lázaro Carreter en distintos periodos para dar cuenta de las nuevas incorporaciones al Diccionario. Tras una exposición teórica sobre este tipo de metáfora tan poco estudiada, el trabajo muestra el papel que desempeñan dichas metáforas como elementos argumentativos. Se muestra hasta qué punto el uso de metáforas sobre la lengua es parte de la construcción tanto de una manera determinada de presentar el idioma como de la forma de actuar de la Academia. De esta forma, se convierte en un recurso esencial en la transmisión de un imaginario sobre la lengua y sobre la Academia que justifica la actividad institucional en la que se implican. El trabajo muestra, además, la vitalidad de las metáforas metalingüísticas tradicionales, ancladas en dominios de origen que proporcionan escenarios seguros y comprensibles para transmitir una determinada idea sobre la lengua.

"El discurso sexista en los artículos de opinión (del masculino genérico, de los desdoblamientos morfológicos y de las duplicidades léxicas)", de José Joaquín Martínez Egido, analiza bajo la óptica del análisis metalingüístico de los textos, el tratamiento y la postura de los articulistas de la prensa española ante el discurso sexista, con el objetivo de configurar la posición ideológica de los autores respecto a la norma lingüística del español, su actitud y los recursos lingüísticos que utilizan al abordar esta temática, concretamente en lo relativo al masculino genérico, a los desdoblamientos morfológicos y a las duplicidades léxicas. El corpus lo componen 150 artículos y columnas publicadas en la prensa española en los últimos 20 años. 
Las conclusiones obtenidas desvelan que las opiniones oscilan desde las posturas más puristas a la más abiertas, pero también que, conforme avanza el tiempo, y con él la necesidad de dar visibilidad a la mujer, aumenta la aceptación de los procedimientos igualitarios. De hecho, los columnistas más puristas van dejando de serlo y atenúan sus opiniones, pues asumen que, si la realidad social de la mujer cambia, la realidad lingüística se transforma inevitablemente con ella.

El artículo de María Antonia Martínez Linares, denominado "Sobre el componente valorativo de los predicados verbales en los debates sobre el lenguaje no sexista y los recursos gramaticales", indaga en las valoraciones negativas que aportan algunos predicados verbales sobre el uso de las formas desdobladas y otros recursos gramaticales relacionados con el lenguaje inclusivo. El corpus lo componen textos procedentes de blogs, de artículos de prensa y de revistas lingüísticas que reflejan dos posturas encontradas sobre esos temas. El análisis ha permitido subrayar algunas de las ideas o creencias compartidas de quienes defienden el lenguaje inclusivo y de quienes lo combaten; dichas valoraciones no se ciñen únicamente a los efectos que esas propuestas gramaticales puedan tener en el funcionamiento de la lengua, sino que se hacen extensivas a los colectivos, instituciones y personas que apoyan o critican las propuestas y sus efectos en la sociedad. Ambas partes presentan coincidencias en algunas de las ideas que configuran la visión negativa de los otros; por un lado, la hipocresía, la falsedad o la discordancia entre los objetivos manifestados; por otro lado, la dureza, la agresividad y la obstinación en la defensa de los planteamientos propios y el rechazo de las estrategias opuestas. Del mismo modo, ambas partes sienten la imposición de los argumentos de la parte contraria sobre la sociedad y sus hablantes.

En el marco del estudio sobre el columnismo lingüístico y su papel en la transmisión de ideologías sobre la lengua, Ana Pano Alamán, en "Marcas polifónicas en las columnas sobre la lengua en la prensa española", presenta los resultados de un análisis discursivo cualitativo sobre la presencia y funciones de la polifonía en un corpus de CSL publicadas en la prensa española por lingüistas, académicos, filólogos, periodistas y escritores en un lapso de cuarenta años. Su objetivo es comprobar hasta qué punto la polifonía es una estrategia pragmáticoenunciativa caracterizadora de las CSL publicadas durante décadas en la prensa española. Tras un marco teórico en el que muestra los distintos tipos de estrategias polifónicas presentes en los textos periodísticos, analiza las 150 columnas seleccionadas. Esto le permite comprobar, por una parte, el valor argumentativo y persuasivo que estas tienen como formas de aproximación al lector; y por otra, la presencia mayoritaria del estilo directo prototípico de reproducción del discurso ajeno. Junto a esta, la autora detecta otras estrategias de igual valor persuasivo como la oralidad fingida, el perspectivismo dialógico con efecto humorístico, el uso de enunciados interrogativos o la ironía.

A partir de una metáfora sobre la construcción (el pensamiento es un edificio), Dolors Poch Olivé se propone mostrar en su trabajo "Los pilares de la lengua. El paso del tiempo y las columnas lingüísticas" de qué manera dos columnistas sobre la lengua pertenecientes a épocas distintas como son Fernando de Araujo y Javier Marías, han coincidido en ocuparse en sus escritos periodísticos de muy parecidas "grietas" del lenguaje. Esto le permite ofrecer un análisis diacrónico y contrastivo, caracterizar y definir el género del columnismo lingüístico a lo largo del tiempo y evidenciar la secular preocupación normativista sobre la lengua. Fernando de Araujo escribió en la sección "Revista de Revistas" de La 
España Moderna desde 1898, pero fue a partir de 1907 cuando intensificó la publicación de artículos sobre tema lingüístico de los que la autora reúne setenta. Por su parte, Javier Marías, escritor y académico, vio recopiladas sus columnas de tema lingüístico publicadas en el diario El País en el volumen Lección pasada de moda. El análisis muestra la recurrencia de errores, como "deber" o "deber de", y de temas, como la lengua de los políticos o los neologismos, lo que evidencia, como concluye la autora, la existencia en este tipo de textos de un imaginario de lengua mejor que la contemporánea a la que los autores siempre parecen querer volver.

Carmen Sánchez Manzanares aborda el discurso político en su artículo "Las columnas de la lengua del Marqués de Tamarón y de Álex Grijelmo sobre comunicación política: la 'lengua' de los políticos en cuestión”. Se basa en una selección de columnas sobre la lengua publicadas en la prensa nacional por el Marqués de Tamarón y Álex Grijelmo, que escriben, respectivamente, en los años ochenta del siglo XX y en las primeras décadas del siglo XXI. Estas columnas nos alertan sobre los modos comunicativos de los políticos y despiertan la inquietud y curiosidad ante ellos. El estudio muestra que el Marqués de Tamarón opta por una caracterización sociológica del habla "incorrecta" de los políticos con el propósito de interpretar los cambios sociales que inducen la jerga política. Sin embargo, el cometido de Grijelmo es el de prevenirnos sobre la manipulación y dotarnos de recursos para defendernos. En cualquier caso, los dos columnistas son creadores de opinión pública: ambos observan la manipulación lingüística por imprecisión semántica como un ejercicio normalizado en la comunicación política, insisten en la obligación de llamar a las cosas por su nombre para evitar la ambigüedad y argumentan mediante una deslegitimación moral de la mentira.

En definitiva, este monográfico quiere ser una aportación al estudio del discurso metalingüístico en la prensa, de su valor como transmisor de ideologías que, finalmente, no son sino el reflejo de lo que en cada momento histórico los hablantes de una comunidad lingüística piensan sobre su propia lengua. 